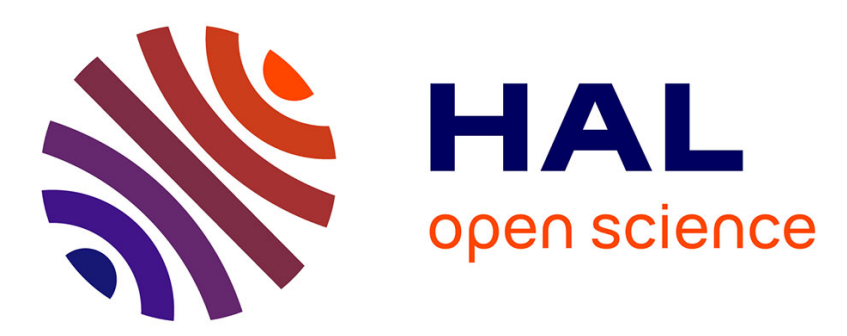

\title{
Addendum - Static magnetic susceptibility of 1.1 diphenyl-2-picryl hydrazyl recrystallized powders B.N. Misra, S.K. Gupt
}

\section{To cite this version:}

B.N. Misra, S.K. Gupt. Addendum - Static magnetic susceptibility of 1.1 diphenyl-2-picryl hydrazyl recrystallized powders. Revue de Physique Appliquée, 1973, 8 (4), pp.391-391. 10.1051/rphysap:0197300804039100 . jpa-00243701

HAL Id: jpa-00243701

https://hal.science/jpa-00243701

Submitted on 1 Jan 1973

HAL is a multi-disciplinary open access archive for the deposit and dissemination of scientific research documents, whether they are published or not. The documents may come from teaching and research institutions in France or abroad, or from public or private research centers.
L'archive ouverte pluridisciplinaire $\mathbf{H A L}$, est destinée au dépôt et à la diffusion de documents scientifiques de niveau recherche, publiés ou non, émanant des établissements d'enseignement et de recherche français ou étrangers, des laboratoires publics ou privés. 


\section{ADDENDUM}

\section{STATIC MAGNETIC SUSCEPTIBILITY OF 1.1 DIPHENYL-2-PICRYL HYDRAZYL RECRYSTALLIZED POWDERS}

B. N. MISRA, S. K. GUPTA

La mesure physique présentée dans cet article avait déjà été entreprise par MM. MARCHAND, PACAULT et ZANCHETTA et publiée dans une note aux Comptes Rendus 258 (1964) 1496. Cependant nous devons signaler que notre étude explore une variété nettement plus grande de solvants et, de plus, tente de corréler les mesures statiques et les caractéristiques des spectres RPE. 